\title{
Nanomole per Milliliter per Hour
}

National Cancer Institute

\section{Source}

National Cancer Institute. Nanomole per Milliliter per Hour. NCI Thesaurus. Code C85757.

Nanomoles per milliliter per hour. 